\title{
O VÉU QUE TECE O DESEJO: APROXIMAÇÕES ENTRE CINEMA E PSICANÁLISE
}

\author{
PEREIRA, C.L..$^{1}$; VIEIRA, H.C. ${ }^{2} \&$ MENEZES, T.P. ${ }^{3}$
}

${ }^{1}$ Professora Adjunta do Departamento de Psicologia (UFC), Membro do Corpo Freudiano Escola de Psicanálise; ${ }^{2}$ Graduando em Psicologia pela Universidade Federal do Ceará, Membro do Laboratório de Psicanálise da UFC; ${ }^{3}$ Graduado em Psicologia pela Universidade Federal do Ceará, Ex-bolsista do Projeto de Extensão Cine Freud Cultural e Arte.

Artigo submetido em 02/09/2018

\section{RESUMO}

$\mathrm{O}$ artigo objetiva elucidar um conceito importante na teoria psicanalítica, o de "fantasia", que se relaciona a outros conceitos basilares desta perspectiva teórica e clínica - como os conceitos de realidade psíquica e de pulsão - a partir do estudo de aspectos formais de duas obras cinematográficas: Elle (2017), do diretor Paul Verhoeven e Estrada Perdida (1997), de David Lynch. Quando acompanhamos aspectos do debate entre cinema e psicanálise, observamos a presença significativa da noção de fantasia. Esse trabalho investiga esta noção em suas relações com aspectos formais destas duas obras cinematográficas. Deste modo, o trabalho se insere no âmbito dos estudos e pesquisas empreendidas pela equipe do projeto e, metodologicamente, irá se utilizar da pesquisa bibliográfica realizada nos grupos de estudo e na transcrição dos debates realizados.

PALAVRAS-CHAVE: Cinema. Psicanálise. Fantasia. Elle. Lost Highway.

\section{VEIL WEAVING DESIRE: APPROXIMATIONS BETWEEN CINEMA AND PSYCHOANALYSIS}

\begin{abstract}
The article aims to elucidate an important concept in psychoanalytic theory, that of "fantasy", which is related to other basic concepts of this theoretical and clinical perspective - such as the concepts of psychic reality and drive - From the study of formal aspects of two cinematographic works: Elle (2017), by director Paul Verhoeven, Lost Road (1997) by David Lynch. When we follow aspects of the debate
\end{abstract}

\begin{abstract}
between cinema and psychoanalysis, we observe the significant presence of the notion of fantasy. This work investigates this notion in relations with formal aspects of these two cinematographic works. In this way, the work is part of the studies and research undertaken by the project team and, methodologically, will be used in the bibliographic research carried out in the study groups and in the transcription of the debate.
\end{abstract}

KEYWORDS: Cinema. Pshychoanalysis. Fantasy. Elle. Lost Highway.

\section{INTRODUÇÃO}

O projeto de extensão "Cine Freud, Cultura e Arte", vinculado ao Laboratório de Psicanálise da Universidade Federal do Ceará (UFC), objetiva estabelecer uma aproximação entre a Psicanálise e a Arte e, especialmente, o Cinema. Permeado por esse diálogo, o Projeto exibe semanalmente, às quartas-feiras, um filme; após o filme ocorre um debate ministrado por psicanalistas e convidados que estabelecem articulações entre outras áreas e a perspectiva psicanalítica. Fazendo parte da programação do Cine Freud no ano de 2017, o filme Elle (2016), de Paul Verhoeven, foi apresentado no primeiro semestre e trouxe como palestrante Joselene Monteiro, contando com um público de 122 pessoas. O filme Estrada Perdida (1997), de David Lynch, foi apresentado no segundo semestre e trouxe como palestrante Cibele Vasconcelos, 
contando com público de 55 pessoas.

O primeiro filme Elle (2016) traz a história de Michèle, interpretada por Isabele Huppert, uma mulher que é violentada dentro de sua própria residência por um desconhecido, e seu rosto não é revelado ou identificado. Michèle trabalha em uma empresa de videogames. Nesta empresa faz-se presente vários jogos que envolvem temas relacionados à violência e às agressões. Elle é um filme que abre uma discussão sobre as diferenças entre a cultura de estupro e a fantasia, o que provocou controvérsias desde a sua elaboração. No debate, o público apontou no filme aspectos subversivos e transgressores, pois, sem desconsiderar a violência a que são submetidas as mulheres, o filme não recuaria diante da possibilidade de abordar a fantasia em sua relação com a violência. Já no cinema de Lynch nota-se a abolição dos espaços de demarcação entre a realidade e o onírico. Como um traço do diretor, bem como para alguns surrealistas, o homem é movido pelo acaso e pelo mistério. Estrada Perdida (2017), que começa ao som de I'm Deranged, de David Bowie, é construída de forma sucinta em uma narrativa desconcertante a partir da história de Fred Madison, interpretado por Bill Pullman, que é preso após assassinar sua esposa, Rene, interpretada por Patricia Arquette. No período em que esteve na prisão, Fred acaba se transformando em um jovem mecânico, Pete Dayton, interpretado por Balthazar Getty. A partir daí, passa a viver sua vida sendo perturbado por elementos estranhamente familiares que começam a aparecer diante de seus olhos, em cenas compostas por processos regidos pelo processo primário, como a condensação e o deslocamento. $\mathrm{O}$ estranho familiar comparece numa construção onde há uma destituição das fronteiras entre a vigília e o sono, ficando o espectador numa zona situada entre os dois estados.

A partir destes aspectos destacados nas duas obras, optamos por aprofundar a noção de fantasia, supondo que os filmes testemunham de modo privilegiado seu modo de articulação. Para Freud, fantasia é uma narrativa ou cena que pode ser ou não inconsciente e mostra que nossa constituição depende de nos tornarmos sujeitos de uma ficção fundamental. (RIVERA, 2014 p.134). A noção de ficção tem um peso significativo na clínica psicanalítica e se relaciona com dois conceitos fundamentais na metapsicologia freudiana: realidade psíquica e pulsão. Buscamos respeitar a técnica da psicanálise, que prioriza as incertezas e as interrogações que as obras de arte produzem por meio do seu testemunho. Considerando que o Cinema pode contribuir com a Psicanálise não apenas pelos "conteúdos" da composição dos personagens, mas por sua própria forma, destacamos que: “[...] A análise de uma obra permite, ter acesso às manifestações do saber inconsciente, mas jamais para que analise seu autor" (COUTINHO 2010, p.39). 
Como indicamos, esse trabalho se insere no âmbito dos estudos e das pesquisas empreendidas pela equipe do Projeto. Adotamos como metodologia a pesquisa bibliográfica realizada nos grupos de estudos sobre Psicanálise e Cinema realizados no Laboratório de Psicanálise da Universidade Federal do Ceará. A partir desses encontros, elencamos autores para o aprofundamento teórico, como Slavoj Zizek (sobretudo o livro "Como Ler Lacan"); Marco Antônio Coutinho Jorge (os livros de sua trilogia "Fundamentos da psicanálise de Freud a Lacan" e de modo privilegiado o volume dedicado à clínica da fantasia); Tania Rivera (com textos dos livros “Arte e Psicanálise" e "Cinema, imagem e psicanálise”); e Juan David Nasio (deste, o livro "A fantasia"). Ademais, as falas das palestrantes e do público durante os debates que ocorreram após a exibição dos filmes, por meio da sua transcrição, constituíram um importante material para a elaboração do artigo.

\section{A NOÇÃO DE FANTASIA}

\subsection{A RELAÇÃO ENTRE REALIDADE PSÍQUICA E PULSÃO}

A noção de fantasia se apresenta como um conceito central no escopo da teoria psicanalítica. Além disso, trata-se de um conceito-pivô nos debates com outras áreas de conhecimento. Pode-se então circunscrever que o surgimento do movimento psicanalítico é tributário da apreensão freudiana do papel da fantasia inconsciente no tratamento dos sintomas histéricos. Ora, é fundamental ressaltar aqui o que o Marco Antônio Coutinho nomeou de "ciclo da fantasia" (2010). Escrito no período em que a psicanálise avançava rumo à internacionalização, que durou de 1906 a 1911, esse ciclo surgiu a partir do ensaio sobre a Gradiva e foi encerrado no artigo metapsicológico sobre a fantasia. Destacamos que, durante esse período, Freud empenhou-se a investigar a estrutura da fantasia sob algumas outras perspectivas, por exemplo, na sua relação com o sintoma histérico e a criação poética. Ademais, pode-se notar que a apreensão freudiana de fantasia inconsciente está relacionada a própria formulação dos processos que regem o funcionamento do aparelho psíquico. Por isso, Lacan, no seu texto "alocução sobre as psicoses da criança", trata dessa questão enfaticamente: "o valor da psicanálise está em operar sobre a fantasia" (Lacan, p.364). Nasio propõe uma definição interessante sobre a mesma $(1997, \mathrm{p} .8)$ :

Um pequeno romance de bolso que carregamos sempre conosco e que podemos abrir
em qualquer lugar sem que ninguém veja nada dele, no trem, no café, e o mais
frequentemente em situações íntimas. Acontece às vezes de essa fábula tornar-se
onipresente no nosso espírito e, sem nos darmos conta, interferir entre nós e nossa
realidade imediata. Concluímos então que muita gente vive, ama, sofre e morre sem
saber que um véu sempre deformou a realidade dos seus laços afetivos.

Como indicamos, a noção de fantasia relaciona-se com outros conceitos basilares da 
teoria psicanalítica, como os conceitos de realidade psíquica e de pulsão. Distinta da realidade material, constitui uma forma de existência do sujeito. Roudinesco (2008) pontua esta assertiva ao afirmar que a fantasia é correlata do período de elaboração da noção de realidade psíquica, após o abandono da teoria da sedução, e designa a vida imaginária do sujeito. A partir dessa radicalidade da dimensão da fantasia, isto é, por sua função de determinação da própria realidade psíquica, é que o tratamento criado por Freud passou a se constituir como tratamento psicanalítico. Doravante, a fantasia passa a ser definida, como afirma Marco Antônio Coutinho Jorge (2010), como a articulação entre a pulsão e o inconsciente. A pulsão (trieb), diferente do instinto, é a "carga energética que se encontra na origem da atividade motora do organismo e do funcionamento psíquico inconsciente do homem" (Roudinesco, 1994). Coutinho Jorge, no seu livro (2010), tratou de articular, em uma nova forma, a fantasia com a pulsão de morte. O emparelhamento estrutural, por exemplo, entre a fantasia e o delírio, é proposto a partir da proposição de que fantasia e delírio seriam homólogos na medida em que são construções que evidenciam os esforços simbólicos e imaginários de apaziguamento das invasões inassimiláveis do real. Sendo assim, constituem-se como telas protetoras que possibilitam o liame, lê-se laço social, com o outro e todo o mundo a nossa volta. Zizek, no livro "Como ler Lacan” (2010, p. 73), pontua sobre essa questão:

Isto nos leva a mais uma complicação vital: se o que experimentamos como
"realidade" é estruturado pela fantasia, e se a fantasia serve como crivo que nos
protege, impedindo que sejamos diretamente esmagados pelo real cru, então a própria
realidade pode funcionar como uma fuga de um encontro com o real.

Desta forma, a fantasia, partindo da pergunta sobre o estatuto da realidade, tematiza a possibilidade do apaziguamento das invasões bárbaras do real intolerável, ou então, o apaziguamento da pulsão, a partir da própria realidade, por meio de uma fuga de um encontro com o real.

\subsection{O SONHO, A REALIDADE E O CINEMA}

Freud investiga, por meio do testemunho da obra Gradiva, de William Jensen, delírios e os sonhos, e suas formulações serão apresentadas em "Delírios e sonhos na Gradiva de Jensen" (1906). Este estudo, no qual a fantasia aparece como um tópico central, inicia o chamado "ciclo da fantasia". Norbert, personagem central, sonha que está em Pompéia, antes da destruição, e ali encontra Gradiva, pela qual nutria grande admiração, mas conhecia apenas através do museu como uma mulher esculpida em pedra. $\mathrm{O}$ texto se refere aos delírios diurnos quando Norbert se depara com a própria Gradiva, e se questiona se aquela era a mesma mulher que vira no sonho. Freud, então, não toma a via de que os sonhos podem prever o futuro, 
optando por inquerir sobre o papel do sonho na constituição dos desejos inconscientes.

Zizek, em seu livro "Como ler Lacan” (2010, p. 73), pontua a distinção entre o sonho e a realidade:

\begin{abstract}
$\mathrm{Na}$ oposição entre sonho e realidade, a fantasia está do lado da realidade, e é em sonhos que nos defrontamos com o real traumático - não é que os sonhos sejam para aqueles que não conseguem suportar a realidade, a própria realidade é para aqueles que não conseguem suportar (o real que se anuncia em) seus sonhos. Esta é a lição que Lacan extrai do famoso sonho relatado por Freud em A interpretação dos sonhos, sonhando pelo pai que cai no sono quando vela sobre o caixão do filho. Nesse sonho, seu filho morto lhe aparece pronunciando o terrível apelo: "Pai, não vês que estou queimando?" Ao acordar, o pai descobre que o tecido sobre o caixão do filho pegou fogo porque uma vela havia caído. Então por que o pai acordou? Teria sido porque o cheiro de fumaça estava muito forte, de modo que não foi mais possível prolongar seu sono encerrando o evento num sonho improvisado?
\end{abstract}

O sonho é o ordenamento de um relato estrutural que se preocupa em mostrar o que o sujeito deseja, numa exibição deles a partir das imagens, elaboradas a partir de processos privilegiados pelo processo primário: "O sonho apresenta uma produção singular de imagens em movimento de caráter alucinatório" (RIVERA, 2011; p.19).

\title{
3. MATERIAS E MÉTODOS
}

Através dos filmes Elle, de Paul Verhoven, e Estrada Perdida, de David Lynch, exibidos no Cine Freud, no Auditório José Albano da Universidade Federal do Ceará, estabelecemos, por meio de seus testemunhos, a temática a ser investigada: o conceito de fantasia, que se relaciona a outros conceitos basilares da perspectiva teórica que orienta a Psicanálise, como os conceitos de realidade psíquica e de pulsão. Isolando elementos que compareceram nos debates realizados após as sessões e e aprofundando a categoria da fantasia no âmbito do Grupo de Estudos da equipe do Cine Freud, ordenamos o percurso de estudo e a forma da exposição dos resultados. Algumas obras foram privilegiadas na pesquisa bibliográfica: Fundamentos da Psicanálise: a clínica da fantasia, de Marco Antônio Coutinho Jorge; Como ler Lacan, de Slavoj Zizek; Cinema, Imagem e Psicanálise, O Avesso do Imaginário, e Arte e Psicanálise, de Tânia Rivera; e A fantasia, de Juan David Nasio. Destacamos, ainda, a importância da transcrição das falas de Joselene Monteiro e de Cibele Vasconcelos, por contribuírem com as formulações que produziram sobre os filmes.

\section{RESULTADOS E DISCUSSÕES}

De uma pergunta inicial sobre o que a arte, por meio do testemunho da alteridade, pode ensinar à psicanálise, nos dirigimos ao Cinema, em especial, encontrando um primeiro ponto de aproximação: o cinema é oriundo da mesma época do surgimento da teoria psicanalítica. 
Estudando autores dos dois campos, foi possível recolocar muitas questões em torno das noções de representação e de realidade. Percebemos que o interesse no diálogo reside muitas vezes na abordagem que a psicanálise empreende do sonho e da realidade. Ora, tal diálogo não se dá por acaso. Se a psicanálise influenciou esse debate em torno da representação nas artes e, particularmente, no cinema, por outro lado, o mesmo aportou contribuições importantes à psicanálise, justamente porque sua "forma" demonstra e ensina sobre os mecanismos de formação dos sonhos e ensina sobre a figurabilidade. Coutinho Jorge (2010, p. 39) observa, sobre as relações entre Arte e Psicanálise:

A arte pode servir para o psicanalista colher um testemunho do inconsciente, mas jamais que analise seu autor. Dito de outro modo, a análise de uma obra permite ter acesso às manifestações do saber inconsciente, mas não analisar o sujeito em questão: a análise de um sujeito não pode prescindir de sua palavra falada e de suas associações.

Não partimos de um modo grosseiro de se fazer uma análise, como em uma psicanálise selvagem, das obras em questão. Partimos da premissa de um "testemunho do inconsciente" que a obra nos permite observar.

É através dessa observação que o filme Elle (2016) põe em discussão o conceito de fantasia. Dunker (2018) salienta que, ao tocarmos no que representa esse conteúdo da fantasia, que a mesma é inerente ao desejo do Outro. No filme, logo após a exibição dos créditos iniciais, a câmera é posicionada para uma violência, um abuso sexual sobre a tela. A personagem, Michele, é violentada dentro da sua residência. Joselene Monteiro (2017) apresenta uma das principais críticas que o filme recebe, a de supostamente compactuar com a cultura do estupro. Além disso, fala das dificuldades do diretor em executar a obra. Citando uma frase do Verhoeven, ela acrescenta:

Como não nos deixamos levar, pela tentação de fazer um filme de vingança, não conseguíamos a simpatia de ninguém nos Estados Unidos, acho que a ideia de uma heroína que estende a mão a um criminoso, ao invés de caçá-lo ou denunciá-lo à polícia, era inaceitável do ponto de vista moral americano. (informação verbal).

Para falar sobre o filme, Silva (2017) fez breves considerações sobre a dinâmica de construção do filme, mais além de uma tomada de posição fechada diante dos sentidos que a obra possa favorecer. Fundamentando seu discurso pela posição ou viés da fantasia, esta que se coloca e apresenta a Outra cena, demarca que a realidade psíquica se difere do material. Outro aspecto alinha-se justamente ao conceito de cultura de estupro, e citando Dunker em sua fala, pondera que esta

Designa a força de coerção que associa masculinidade com a submissão, dominação ou a capacidade de exercer poder e violência contra a mulher. Isso se refere também à leniência e naturalidade com a qual interpretamos atos de violência particular como uma tendência universal, integrando-os ao cotidiano, naturalizando-os e neutralizando nossa capacidade de indignação e a potência transformativa que esperamos de cada 
forma de sofrimento. (informação verbal).

Silva (2017) nos aponta uma diferenciação que é crucial para compreendermos a fantasia em sua relação com uma cena que presentifica o desejo do Outro:

\begin{abstract}
Para além de borrar as fronteiras entre homem e monstro, considero também que esse filme evidencia claramente que a fantasia, envolve necessariamente a fantasia do outro. Dito, de outra forma não é questão de ter acesso ao outro objeto, mas ter acesso a posse que eu suponho do desejo do outro. Considerando a dupla volta, da fantasia para Lacan na qual, além da suposição sobre: o que eu quero, há também a suposição o que o outro quer, nesse sentido, um recurso valioso da direção foi a alternância entre os pontos de vistas, como também, esse jogo alternado de questões sobre o desejo do outro. Desse jeito que nas cenas de agressões sobretudo a câmera vinha pro lado dela e depois ia pro lado dele. É um recurso de direção que ajuda a gente se posicionar para os dois lados, e tentar entender a trama sobre os dois pontos de vistas. (informação verbal)
\end{abstract}

No filme Estrada Perdida (1997) podemos perceber um duplo diálogo que atravessa uma narrativa onírica e um cotidiano inopinado. Notamos que Lynch explora de maneira singular o encontro de imagens e de sons. A desordem e a ausência de sentido são mecanismos próprios da narrativa. Temos como produto disso o universo do sonho sendo confundido com aquilo que é parte do cotidiano. Tal estranhamento pode gerar um incômodo, certo mal-estar. É uma obra onde o não sentido é soberano. Tal fato é perceptível na fala de Cibele:

Falar dos filmes do Lynch, ou tentar elaborar e pôr no campo dos sentidos, aquilo que se submeter a esses filmes nos causa, na posição em que nós estamos que é de espectadores, mostra-se uma tarefa da ordem do impossível, talvez por sua singular lógica da ordem de construção, a qual ele nos desvela e nos joga em um completo nonsense. Ou porque corremos um risco de despedaçar uma construção delicada e de formato único que os filmes do Lynch têm. Sendo assim, o que é que a gente poderia fazer para sair dessa posição dicotômica, de super interpretar esse filme, como se a cada frame a gente pudesse fazer um mini discurso sobre ele, ou então não falar nada, se é tão sem sentido não vamos falar nada. (informação verbal).

Marco Antônio Coutinho Jorge (2017) nomeia David Lynch como um grande mestre do estranho, mestre de obra onde a trilogia silêncio-solidão-escuridão é explorada constantemente. O filme é construído por cenas que remetem à escuridão, de modo que suspenda paulatinamente o sentido da narrativa. É essa suspensão do juízo, da consciência, que abre espaço de uma cena para Outra Cena, o inconsciente. O filme de Lynch nos remete a uma experiência sensorial sob a qual temos que nos deixar levar. Percebemos tal fato ao iniciarmos a película, já nas primeiras cenas do filme, numa narrativa cuja abertura já é desconcertante. Imagens e sons se somam causando certos efeitos nos espectadores. Cibele, em sua fala, levanta suas impressões acerca do início do filme:

Bem nos primeiros minutos, temos uma estrada sendo atravessada em alta velocidade. De início se perguntamos sobre o que se trata essa estrada, esse filme seria um road, um típico filme hollywoodiano de estrada. Nas interrogações que ficam, é qual é essa estrada, porque a estamos atravessando. Porque as tomadas que o Lynch escolhe de câmeras, elas são muito introspectivas, então, parte de um ponto de vista que você fosse o próprio carro atravessando a estrada. Porque estaríamos atravessando e para onde ela então nos levaria, supondo que nós estamos nesse barco do Lynch, não é. Ao decorrer dessa opening não é, que não deixa de ser uma abertura do filme, a estrada 
acaba sendo atravessada mais rápido, de forma que sua estrutura e sua forma vai

ficando borrada, e aos poucos não sabemos mais ao certo se é uma estrada mesmo.

Nós, espectadores, encontramo-nos na fronteira entre a consciência e uma Outra cena, onírica. Entre o sentido e o não sentido. Entre aquilo que parece absurdo e aquilo que é cotidiano e familiar. Lynch, ao som de David Bowie, nos hipnotiza por meio das faixas amarelas da estrada que são iluminadas pelos faróis de um carro. Na medida em que os créditos vão passando, a estrada fica cada vez mais borrada. Como se a estrada, elemento cotidiano, deixasse de ser uma estrada. O filme inteiro é construído assim.

Uma das últimas cenas do filme se passa numa cabana de madeira isolada no meio do deserto. Na presente cena, podemos observar aspectos da realidade estruturados pela fantasia:

A cena se passa numa cabana de madeira no deserto. A precariedade da construção num meio tão inóspito só pode ser associada ao reduto da fantasia (cabana) no qual o sujeito se abriga como pode do real (deserto). Pete e Alice se amam no chão de areia, e, quando ele diz a ela "Eu quero você", ela responde com uma expressão fácil de gozo: "Você nunca me ter". Alice desaparece na cabana, pois a fantasia é o único lugar em que o homem encontra a mulher. Mas esta não pode ser inteiramente apreendida pela fantasia masculina: há algo nela que escapa ao registro fálico, e a isso o homem não tem acesso. (COUTINHO JORGE, 2017, p.199).

A Cabana precária localizada no meio do deserto, de acordo com Coutinho Jorge (2017), é um reduto da fantasia, da qual o sujeito se utiliza como forma de apaziguamento do real, de apaziguamento da pulsão.

\section{CONCLUSÃO}

O presente trabalho permitiu a articulação entre a arte, a psicanálise e o cinema, tomando como eixo a fantasia, a realidade psíquica e a pulsão. As obras cinematográficas de Paul Verhoven, Elle (2016), e de David Lynch, Estrada Perdida (1997), serviram como testemunho destas noções a partir de suas construções cênicas e dos temas abordados. Considerando que os dois filmes permitiram aprofundar a relação proposta de modo privilegiado, realizamos esse recorte. Enfatizamos, ainda, que os filmes foram discutidos em relação com a perspectiva dos dois diretores, tendo em vista o lugar que ocupam nos debates que se inserem no campo da crítica cinematográfica e da crítica da cultura.

O cinema de Paul Verhoeven opera a partir de fragmentos e de uma cena que funciona como trauma incidindo um corte e desestabilizando uma narrativa linear. O sentido é construído a posteriori e, coerente com essa proposição de que o sentido é construído num só-depois, o sentido que então é construído sofre de uma fratura interna, correlativa ao que a Psicanálise irá conceber como a divisão do sujeito. O cinema de Verhoeven é considerado como amoral e pervertido por não seguir uma lógica moral, visto a rejeição de sua película por alguns críticos. 
O que foi possível levantar como questão, após o trabalho que realizamos, é que talvez não se trate de não seguir determinada posição ou de ser leviano com questões que merecem seriedade, mas, de fato, de interrogar o lugar da produção do sentido. Diante da realidade, a técnica de Verhoeven parece incidir justamente no estatuto desta realidade. A realidade e o sentido passam a ser questionadas, numa operação de fratura que indica que uma cena pode assumir diferentes sentidos, dependendo do ponto de vista. O que nos parece crucial, no entanto, é que este ponto de vista diferente não se situa somente entre o eu e o outro (meu semelhante), mas entre o eu e o sujeito (esse corte que divide o próprio aparelho psíquico). Esta divisão, manejada pelo diretor na composição das cenas que se comportam como fantasias, implica, segundo nossa leitura, o comparecimento dessa Outra cena - o comparecimento do Inconsciente. Podemos dizer que Verhoeven testemunha sobre a fantasia como cena que articula o desejo ao desejo do Outro. A composição de Outra cena - ou a composição da cena como Outra - é realizada com o recurso, caraterístico desta direção, da mudança na posição das câmeras.

O filme de Lynch pareceu nos colocar diante de uma tarefa impossível, se a tarefa for a de transpor para o sentido aquilo que o filme transmite para nós, como expectadores. Isso porque a sua lógica singular de construção de uma narrativa nos instiga a uma provocação sobre aquilo que não tem sentido. Talvez este seja um primeiro passo na direção de poder formular alguma coisa. Estrada perdida é um filme que nos convida à decifração. Um enigma. Faz-nos querer inventar soluções ao penetrar seu mistério. O que tentamos fazer para sair dessa posição desconfortável, da exigência de jogar uma interpretação a esse filme, foi apreender que sofremos os efeitos do seu testemunho, ou seja, apreendemos que Lynch nos lança numa experiência onírica. Deste ponto, se colocam desafios futuros, que fogem ao escopo deste trabalho, de construir um desenho, digamos, das operações privilegiadas nessa forma cinematográfica, pois foi possível perceber a prevalência de operações que de deslocamento e de condensação. $\mathrm{O}$ aspecto semântico, neste filme, cede seu lugar de primazia para acolher outras formas próximas à do chiste, do sonho, da fala da criança.

\section{REFERÊNCIAS}

ELLE. Direção de Paul Verhoeven. Realização de Saïd Ben Saïd, Michel Merkt. Coordenação de Thanassis Karathanos, Sébastien Delloye. Intérpretes: Isabelle Hupert, Laurent Lafitte, Anne Consigny, Charles Berling, Virginie Efira, Christian Berkel, Judith Magre, Jonas Bloquet, Alice Isaaz. Roteiro: David Birke. França, Alemanha: Sony Pictures, 2016. (130 min.), son., color. Legendado.

DUNKER, Christian. A fantasia do estupro e a cultura do estupro: No mês da mulher é bom rever o filme Elle (2016), de Paul Verhoeven que traz à tona a discussão sobre a cultura 
do estupro e a necessidade de possuir o desejo do outro. 2018. Disponível em:

<http://www.paginab.com.br/opiniao/fantasia-do-estupro-e-cultura-do-estupro/>. Acesso em: 01 set. 2018.

FREUD, Sigmund. O delírio e os sonhos na gradiva de W. Jensen. In: FREUD, Sigmund. O delírio e os sonhos na Gradiva, análise da fobia de um garoto de cinco anos e outros textos: (1906-1909) Volume 8. São Paulo: Companhia das Letras, 1907/2015. p. 9-119. Tradução Paulo César de Sousa.

JORGE, Marco Antônio Coutinho. Fundamentos da psicanálise de Freud a Lacan. vII: a clínica da fantasia. Rio de Janeiro: Jorge Zahar, 2010.

JORGE, Marco Antônio Coutinho. Fundamentos da psicanálise de Freud a Lacan. vIII: a prática analítica. Rio de Janeiro: Jorge Zahar, 2017.p. 196-199.

LACAN, Jacques. Alocução sobre as psicoses das crianças. In: LACAN, Jacques. Outros Escritos. Rio de Janeiro: Jorge Zahar, 1967/2003. p. 361-370. Tradução: Vera Ribeiro, Angelina Harari e Marcus André Vieira.

LOST HIGHWAY. Direção: David Lynch. Produção: Mary Sweeney, Tom Sternberg e Deepak Nayar. Interpretes: Bill Pullman; Patricia Arquette; David Lynch e outros. Roteiro: David Lynch e Barry Gifford. [Estados Unidos e França]: Ciby 2000; Asymmetrical Productions; Lost Highway Productions; October Films, 1997. DVD (2h15m)

NASIO, Juan-David. A fantasia. Rio de Janeiro: Zahar, 1997.

RIVERA, Tania. Sublimação, espaço, fantasia. In: RIVERA, Tania. avesso do imaginário: Arte contemporânea e psicanálise. 2. ed. São Paulo: Cosac Naify, 1969/2014. p. 105-153

RIVERA, Tania. Cinema, Imagem e Psicanálise.2. ed. Rio de Janeiro: Zahar, 2011. P. 76

ROUDINESCO, E; PLON, M. Dicionário de psicanálise. Tradução Vera Ribeiro; Lucy Magalhães. Rio de Janeiro: Jorge Zahar, 1998. p. 223-226.

SILVA, J. M. Cine Freud 2017.1: Elle. Palestra gravada e proferida no dia 19 de abril de 2017, no Auditório José Albano, na Universidade Federal do Ceará (UFC).

VASCONCELOS, C. M. G. Cine Freud 2017.2: Estrada Perdida. Palestra gravada e proferida no dia 29 de novembro de 2017, no Auditório José Albano, na Universidade Federal do Ceará (UFC).

ZIZEK, Slavoj. Como ler Lacan. Tradução Maria Luiza X. de A. Borges. Rio de Janeiro: Jorge Zahar, cap. III 2010. p. 53-77. 